\title{
Penerapan Data Mining Untuk Memprediksi Penerimaan Peserta Didik Baru Menggunakan Algoritma C4.5
}

\author{
Riki Winanjaya, Faisal Amir, Rahmad Doni \\ AMIK Tunas Bangsa, Pematang Siantar, Universitas Potensi Utama, Medan \\ Winanjaya85@gmail.com, Faisalamir5pr@gmail.com, rahmaddoni113@gmail.com
}

\begin{abstract}
Hasanah Vocational High School (VHS) is a school that has been accredited A Excellent. But New Student Admission (NSA) has some difficulties in knowing the potential of students who will attend school. This is due to inconsistent selection and subjective judgments. Therefore a method is needed to identify new prospective students at school. Data Mining with C4.5 Algorithm can be used to make predictions and classifications of prospective new students in school by making decision trees based on existing data and predicting new prospective students who want to go to school. Data on prospective students who register through the regular path of the 2018/2019 school year. The results obtained are variables that have the highest priority on the predictions of NSA are prospective students who test scores with high scores so the student is declared an accepted status.
\end{abstract}

Keywords: C4.5 Algorithm, Data Mining, New Student Admission (NSA), Prediction

Abstrak- Sekolah Menengah Kejuruan (SMK) Hasanah merupakan sekolah yang sudah terakreditasi A Unggul. Namun Penerimaan Peserta Didik Baru (PPDB) terdapat beberapa kesulitan untuk mengetahui potensi siswa yang akan bersekolah. Hal ini dikarenakan pemilihan yang tidak konsisten dan penilaian yang bersifat subjektif. Oleh karena itu diperlukan metode untuk mengidentifikasi calon siswa baru di sekolah. Data Mining dengan Algoritma C4.5 dapat digunakan untuk melakukan prediksi dan klasifikasi terhadap calon siswa baru di sekolah dengan cara membuat pohon keputusan berdasarkan data-data yang sudah ada dan melakukan prediksi terhadap calon siswa baru yang ingin masuk ke sekolah. Data calon siswa yang mendaftar melalui jalur reguler tahun ajaran 2018/2019. Hasil yang didapatkan adalah Variabel yang memiliki prioritas utama terhadap prediksi PPDB adalah calon siswa yang Nilai tes dengan Nilai tinggi maka siswa tersebut dinyatakan dengan status diterima.

Kata kunci: Algoritma C4.5, Data Mining. Penerimaan Peserta Didik Baru(PPDB), Prediksi

\section{PENDAHULUAN}

Penerimaan Peserta Didik Baru (PPDB) yang ada di Sekolah Menengah Kejuruan (SMK) Hasanah Pekanbaru disediakan dalam beberapa jalur seperti Jalur Beasiswa, Mandiri dan Reguler. Pada penelitian ini akan membahas khususnya jalur Reguler. Dalam kegiatannya proses peneriaan PPDB dengan jalur reguler masih dilakukan secara manual dimana calon siswa datang langsung ke sekolah dan melakukan registrasi dan dilakukan beberapa tes. Sehingga memungkinkan hasil seleksi yang subjektif dan tentunya akan memakan waktu pengerjaan yang lama. Sehingga diperlukan sebuah metode yang dapat mengatasi masalah tersebut 
agar hasil yang diperoleh menjadi lebih objektif, akurat dan dapat mempersingkat waktu.

Suatu hal yang penting seharusnya dilakukan sekolah pada saat melakukan PPDB, yaitu dengan mengidentifikasi pola dari data PPDB yang sudah dilaksanakan, dengan melakukan klasifikasi dari variabel yang ditentukan. Informasi yang dapat diterima sekolah dari penentuan tersebut dapat dijadikan dasar penentuan kebijakan sistem PPDB yang akan dating untuk kriteria penerimaan calon siswanya. Salah satu Teknik klasifikasi yang sering digunakan oleh peneliti adalah penerapan algoritma C4.5. Algoritma C4.5 adalah algoritma yang menghasilkan pohon keputusan, memiliki masukan berupa sampel klasifikasi [3]. Algoritma C4.5 yaitu metode pohon keputusan mengubah fakta yang sangat besar menjadi pohon keputusan yang merepresentasikan aturan [4]. Penelitian terdahulu Algoritma C4.5 dapat membantu untuk mengambil keputusan penerimaan mahasiswa baru yang dapat lulus tepat waktu dan mahasiswa yang lulus terlambat dapat terprediksi lebih awal [5]. Algoritma C4.5 dapat digunakan sebagai metode klasifikasi dalam memprediksi profit perusahaan dengan memperhatikan nilai gain tertinggi dari tujuh atribut yaitu biaya tenaga ahli, biaya tenaga Teknik, biaya tenaga pendukung, biaya operasional kantor, biaya peralatan, biaya pelaporan dan dokumen, dan biaya mobilisasi [6].

Algoritma C4.5 digunakan pada penelitian ini untuk memprediksi penerimaan peserta didik baru pada SMK Hasanah. Algoritma ini menganalisa set data sampel dan membangun sebuah classifier yang harus mempunyai sebuah kapasitas untuk mengatur kasus latihan dan kasus percobaan dengan akurat [9]. Algoritma C4.5 dengan memanfaatkan perangkat lunak RapidMiner dalam menganalisis data rekam medis menghasilkan parameter-parameter keputusan beru pohon keputusan yang baik dalam pengambilan keputusan di RSUD Mayjen H.A. Thalib Kerinci [8].

\section{METODOLOGI PENELITIAN}

Implementasi algoritma C4.5 untuk prediksi penerimaan siswa baru menggunakan langkah-langkah sebagai berikut:

a. Studi Pustaka

Penelitian dimulai dengan mempelajari informasi serta algoritma yang bersangkutan dengan penelitian ini dengan cara membaca jurnal serta beberapa referensi pembelajaran lain. Pada tahap ini konsep-konsep yang dibutuhkan dalam penelitian akan dimatangkan, seperti definisi dari algoritma C4.5 dan penerapannya.

b. Pengumpulan Sampel Data

Pada tahap ini proses pengumpulan sampel data akan dilakukan dengan cara meminta data calon PPDB tahun 2018/2019 langsung kepada pihak sekolah, yakni SMK Hasanah. Data calon PPDB ini mencakup berbagai macam informasi mulai dari nama, asal sekolah, nilai test, pendapatan orang tua, dan atribut lain yang kemudian akan diolah menggunakan algoritma C4.5. Jumlah data yang akan digunakan adalah 30 data calon PPDB. Seperti pada tabel 1. 
Tabel 1. Data Calon PPDB

\begin{tabular}{|c|c|c|c|c|c|}
\hline $\begin{array}{l}\text { Nama } \\
\text { Calon } \\
\text { PPDB }\end{array}$ & Asal Daerah & $\begin{array}{l}\text { Nilai } \\
\text { tes }\end{array}$ & $\begin{array}{l}\text { Pekerjaan Orang } \\
\text { tua }\end{array}$ & Jurusan & Status \\
\hline Siswa 1 & Pekanbaru & Rendah & Karyawan Swasta & TKJ & Ditolak \\
\hline Siswa 2 & Luar Pekanbaru & Sedang & PNS & RPL & Diterima \\
\hline Siswa 3 & Pekanbaru & Tinggi & Karyawan Swasta & RPL & Diterima \\
\hline Siswa 4 & Pekanbaru & Sedang & Karyawan Swasta & TKJ & Ditolak \\
\hline Siswa 5 & Pekanbaru & Sedang & Karyawan Swasta & TKJ & Ditolak \\
\hline Siswa 6 & Pekanbaru & Sedang & Karyawan Swasta & TKJ & Diterima \\
\hline Siswa 7 & Pekanbaru & Sedang & Karyawan Swasta & TKJ & Ditolak \\
\hline Siswa 8 & Luar Pekanbaru & Sedang & Karyawan Swasta & TKJ & Diterima \\
\hline Siswa 9 & Pekanbaru & Sedang & Karyawan Swasta & TKJ & Diterima \\
\hline Siswa 10 & Pekanbaru & Sedang & Karyawan Swasta & RPL & Diterima \\
\hline Siswa 11 & Luar Pekanbaru & Tinggi & Karyawan Swasta & RPL & Diterima \\
\hline Siswa 12 & Luar Pekanbaru & Sedang & Karyawan Swasta & RPL & Diterima \\
\hline Siswa 13 & Pekanbaru & Sedang & Karyawan Swasta & RPL & Diterima \\
\hline Siswa 14 & Pekanbaru & Sedang & Karyawan Swasta & RPL & Ditolak \\
\hline Siswa 15 & Pekanbaru & Tinggi & PNS & RPL & Diterima \\
\hline Siswa 16 & Pekanbaru & Tinggi & Karyawan Swasta & RPL & Diterima \\
\hline Siswa 17 & Pekanbaru & Tinggi & Karyawan Swasta & RPL & Diterima \\
\hline Siswa 18 & Luar Pekanbaru & Tinggi & PNS & TKJ & Diterima \\
\hline Siswa 19 & Pekanbaru & Rendah & Karyawan Swasta & TKJ & Diterima \\
\hline Siswa 20 & Pekanbaru & Sedang & Karyawan Swasta & TKJ & Diterima \\
\hline Siswa 21 & Pekanbaru & Rendah & Karyawan Swasta & TKJ & Ditolak \\
\hline Siswa 22 & Luar Pekanbaru & Rendah & Karyawan Swasta & TKJ & Ditolak \\
\hline Siswa 23 & Luar Pekanbaru & Sedang & Karyawan Swasta & RPL & Diterima \\
\hline Siswa 24 & Pekanbaru & Tinggi & Karyawan Swasta & RPL & Diterima \\
\hline Siswa 25 & Pekanbaru & Tinggi & Karyawan Swasta & RPL & Diterima \\
\hline Siswa 26 & Luar Pekanbaru & Sedang & PNS & RPL & Diterima \\
\hline Siswa 27 & Pekanbaru & Sedang & PNS & RPL & Ditolak \\
\hline Siswa 28 & Pekanbaru & Sedang & Karyawan Swasta & RPL & Diterima \\
\hline Siswa 29 & Pekanbaru & Tinggi & Karyawan Swasta & RPL & Diterima \\
\hline Siswa 30 & Luar Pekanbaru & Sedang & Karyawan Swasta & RPL & Diterima \\
\hline
\end{tabular}

\section{c. Analisis Sampel Data}

Setelah data-data calon PPDB didapatkan, dilakukan pemilahan dan perhitungan atribut data sesuai dengan parameter yang telah ditentukan untuk dilakukan perhitungan nilai entropy dan gain untuk mendapatkan gambaran umum dari suatu set data. Untuk memilih atribut sebagai akar, didasarkan pada nilai gain tertinggi dari atribut-atribut yang ada. Untung menghitung gain digunakan rumus seperti berikut :

$$
\operatorname{Gain}(S, A)=\operatorname{Entropy}(S)-\sum_{i=1}^{n} \frac{|S i|}{|S|} * \operatorname{Entropy}(S i)
$$

Keterangan :

$\mathrm{S}=$ Himpunan Kasus

$A=$ Atribut 
$\mathrm{n}=$ Jumlah partisi atribut $\mathrm{A}$

$|\mathrm{Si}|=$ Jumlah kasus pada partisi ke-i

$|S|=$ Jumlah kasus dalam $S$

Sedangkan perhitungan Nilai Entropy berdasarkan rumus :

$$
\text { Entropy }(S)=\sum_{i=1}^{n}-p i * \log _{2} p i
$$

Keterangan :

$\mathrm{S}=$ Himpunan kasus

$\mathrm{n}=$ Jumlah partisi $\mathrm{S}$

$\mathrm{Pi}=$ Proporsi dari Si terhadap S

Berdasarkan data pada tabel 1, dengan metode algoritma C4.5 yang digunakan, maka perhitungan entropy dan nilai gain masing-masing variabel dapat dilihat pada tabel 2.

Tabel 2. Entropy dan Gain

\begin{tabular}{|l|l|l|c|c|c|c|c|}
\hline $\mathbf{1}$ & TOTAL & & $\mathbf{3 0}$ & $\mathbf{2 2}$ & $\mathbf{8}$ & $\mathbf{0 , 8 3 6 6}$ & \\
\hline & Nilai tes & & & & & & 0,2998 \\
\hline & & Rendah & 4 & 1 & 3 & 0,3112 & \\
\hline & & Sedang & 17 & 12 & 5 & 0,8739 & 0 \\
\hline & Tsal daerah & & 9 & 9 & 0 & 0 & 0,0428 \\
\hline & & Pekanbaru & 21 & 14 & 7 & 0,9182 & \\
\hline & & Luar Pekanbaru & 9 & 8 & 1 & 0,5032 & \\
\hline & $\begin{array}{l}\text { Pekerjaan } \\
\text { orangtua }\end{array}$ & & & & & & 0,0808 \\
\hline & & Karyawan Swasta & 25 & 18 & 7 & 0,8554 & \\
\hline & & 5 & 4 & 1 & 0,2575 & \\
\hline & Jurusan & & & & & & 0,3460 \\
\hline & & TKJ & 12 & 6 & 6 & 1 & \\
\hline & & RPL & 16 & 2 & 0,1510 & \\
\hline
\end{tabular}

Berdasarkan hasil yang didapt pada tabel 2, maka sebagai langkah pertama variabel Nilai tes mnejadi NODE pertama dalam decision tree karena memiliki nilai gain paling tinggi. Pada langkah selanjutnya adalah menentukan NODE kedua dan seterusnya hingga decision tree didaptkan dengan perhitungan cara yang sama pada langkah diatas.

\section{HASIL DAN PEMBAHASAN}

Implementasi dilakukan menggunakan salah satu perangkat lunak Data Mining yaitu RapidMiner. Semua atribut indicator input dan atribut tujuan 
disimpan dalam format xlsx, kemudian import ke software RapidMiner dan menghasilkan decision tree sebagai berikut :

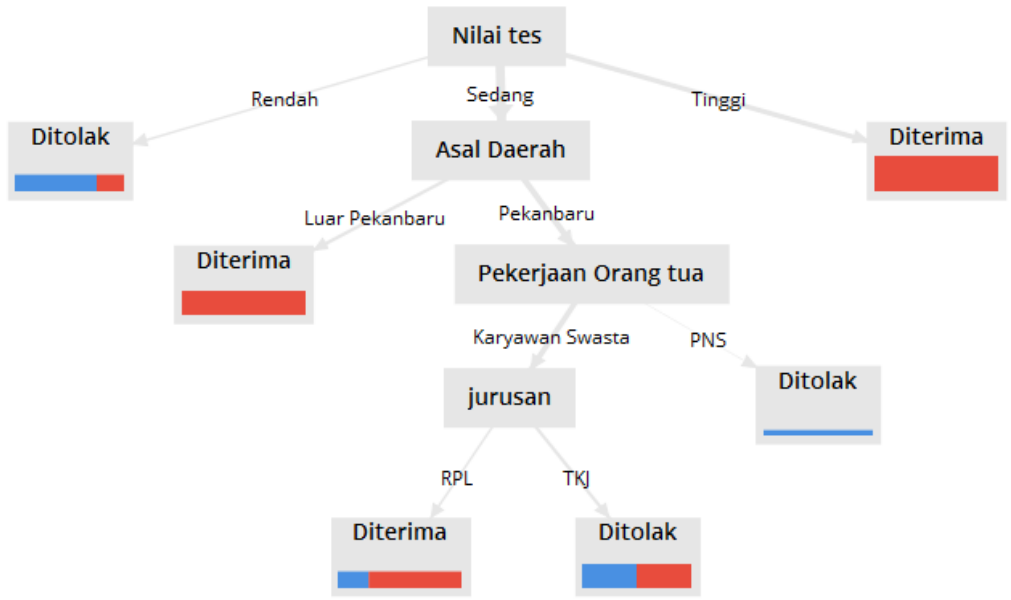

Gambar 1. Pohon Keputusan Prediksi PPDB

Jika dilihat berdasarkan hasil pohon keputusan prediksi PPDB bahwa atribut yang mempunyai pengaruh utama untuk mendapatkan prediksi PPDB adalah variable Nilai tes yang menempati sebagai simpul akar. Agar lebih jelas, peneliti membuat model aturan berupa teks, seperti keterangan dibawah ini :

1. Jika Nilai tes $=$ Rendah maka Status $=$ Ditolak

2. Jika Nilai tes $=$ Sedang dan Asal Daerah $=$ Luar Pekanbaru maka Status $=$ Diterima

3. Jika Nilai tes $=$ Sedang, Asal Daerah $=$ Pekanbaru, Pekerjaan Orang tua $=$ Karyawan Swasta dan Jurusan RPL maka Status = Diterima

4. Jika Nilai tes $=$ Sedang, Asal Daerah $=$ Pekanbaru, Pekerjaan Orang tua $=$ Karyawan Swasta dan Jurusan TKJ maka Status = Ditolak

5. Jika Nilai tes $=$ Sedang, Asal Daerah $=$ Pekanbaru dan Pekerjaan Orang tua $=$ PNS maka Status $=$ Ditolak

6. Jika Nilai tes $=$ Tinggi maka Status $=$ Diterima

Dapat dilihat dari hasil pohon keputusan dan model aturan berbentuk teks bahwa, jika calon PPDB memiliki Nilai tes Tinggi maka calon PPDB tersebut diprediksi Diterima tanpa melihat Asal Daerah, Pekerjaan orangtua dan Jurusan.

\section{KESIMPULAN}

Implementasi algoritma C4.5 untuk melakukan prediksi terhadap penerimaan peserta didik baru pada SMK Hasanah telah berhasil dilakukan. Variabel yang memiliki prioritas utama terhadap prediksi PPDB adalah calon siswa yang Nilai tes dengan Nilai tinggi maka siswa tersebut dinyatakan dengan status diterima dibandingan dengan siswa dengan Nilai sedang. Pengaruhi ini dapat dilihat dari nilai tes yang dihasilkan dari calon siswa dapatkan ketika mengikuti 
proses interview ketika mendaftar di SMK Hasanah. Untuk penelitian selanjutnya, sebaiknya dilakukan uji coba menggunakan sampel data yang lebih banyak dan menentukan tingkat akurasi data serta dibangunnya sebuah sistem aplikasi.

\section{DAFTAR PUSTAKA}

[1] Sinam and Abdulwahab Lawan, "An Improved C4.5 Moodel Classification Algorithm Based On Taylor's Series”, Joedanian Journal of Computer and Information Technology, Vol. 05, No.01, April 2019.

[2] Indra Mukti Prabowo dan Subiyanto, "Sistem Rekomendasi Penjurusan Sekolah Menengah Kejuruan Dengan Algoritma C4.5”, Jurnal Kependidikan, Vol. I, No 1, Hal. 139-149, Juni 2017.

[3] Yudha Aditya Fiandra, Sarjon Defit dan Yuhandri, "Penerapan Algoritma C4.5 Untuk Klasifikasi Data Rekam Medis Berdasarkan Internation Classification Diseases (ICD-10)”, Jurnal RESTI, Vol 1, No. 2, 82-89, 2017.

[4] Rusda Wajhillah dan Ita Yulianti, "Penerapan Algoritma C4.5 Untuk Prediksi Penggunaan Jenis Kontrasepsi Berbasis Web”, Kumpulan Jurnal Ilmu Komputer, Vol.04, No. 02, September 2017.

[5] Yoga Handoko, Agustin, Kusrini dan Emha Taufiq Luthfi, "Klasifikasi Penerimaan Mahasiswa Baru Menggunakan Algoritma C4.5 Dan Adaboost (Studi Kasus ; STMIK XYZ)”, CSRID Journal, Vo.9, No.1, Hal 1-11, Februari 2017.

[6] Erlin Elisa, "Prediksi Profit Pada Perusahaan Dengan Klasifikasi Algoritma C4.5”, Kumpulan Jurnal Ilmu Komputer, Vol. 005, No. 02, September 2018.

[7] Erlan Darmawan, "C4.5 Algorithm Application For Prediction Of Self Candidate New Student In Higher Education”, Jurnal Online Informatika, Vol. 3, No. 1, 22-28, Juni 2018.

[8] Rian Rafiska, Sarjon Defit dan Gunadi Widi Nurcahyo, "Analisis Rekam Medis Untuk Menentukan Pola Kelompok Penyakit Menggunakan Algoritma C4.5”, Jurnal RESTI, Vol. 2, No. 1, 391-396, 2018.

[9] Tomy Salim dan Yo Ceng Giap, "Data Mining Identifikasi Website Phising Menggunakan Algoritma C4.5", Jurnal TAM(Technology Acceptance Model), Vol. 8, Hal. 130-135, Desember 2017.

[10] Rismayanti, “Decision Tree Penentuan Masa Studi Mahasiswa Prodi Teknik Informatika (Studi Kasus : Fakultas Teknik dan Komputer Universitas Harapan Medan)”, QUERY : Jurnal Sistem Informasi, Vol. 02, No. 01, April 2018.

[11] Bambang Hermanto dan Azhari SN, "Klasifikasi Nilai Kelayakan Calon Debitur Baru Menggunakan Decision Tree C4.5”, IJCCS, Vol. 11, No. 01, pp. 43-54, Januari 2017.

[12] Robbi Rahim, et.al, "C4.5 Classification Data Mining For Inventory Control", International Journal Of Engineering \& Technology, Vol. 7, No. 2.3, pp. 68-72, 2018. 